\title{
Solitary papilloma of a bronchus
}

\author{
J. M. DRENNAN AND A. C. DOUGLAS \\ From the Pathology Department, Western General Hospital and Thoracic Unit, \\ Northern General Hospital, Edinburgh
}

SYNOPSIS The cause of asthmatic attacks in a middle-aged man was disclosed and the relief of his symptoms achieved at one and the same time when he coughed up a tumour which proved to be a solitary bronchial papilloma. The pedicle of the tumour had ruptured as the result of infarction due to thrombosis in stromal blood vessels. Asthmatic attacks, stromal blood vessel thrombosis, and the coughing up of the tumour are three features which have not been reported in the few published accounts of this exceedingly rare bronchial tumour.

\section{CLINICAL HISTORY}

The patient, a short, stout man aged 56 , had suffered from mild chronic bronchitis for 10 years and now complained of intermittent attacks of wheezing and dyspnoea which had developed progressively over the previous nine months. Both his parents had been asthmatic, his mother had died in status asthmaticus, and one of his three brothers was a confirmed asthmatic of many years' standing. The patient was convinced that he himself now had the disease. He was referred by his doctor to the Chest Unit of the Northern General Hospital where the initial clinical and radiological examination in the Out-patient Department revealed nothing beyond a moderate degree of emphysema.

A few days later at his home he was seized by a particularly violent attack of wheezing and dyspnoea followed by prolonged coughing which ended with the coughing up of a rounded object about the size of a large marble, covered in blood. For some hours afterwards he continued to expectorate a mucoid sputum tinged with blood. He took the specimen to his doctor who recognized it as a tumour and sent it to the Pathology Department for examination.

Three days after this episode the patient was admitted to hospital for further investigation and a chest radiograph was taken and compared with the earlier film. It was thought that the broncho-vascular markings in the lower lobe of the left lung were less crowded than before, as though a minor degree of collapse in this region had been relieved by the removal of an obstruction. Furthermore, re-scrutiny of the original film revealed a faint rounded opacity at the lower part of the hilum of the left lung, which was not present in the subsequent radiograph. It seemed probable that this opacity was due to the tumour situated near the origin of the left lower lobe bronchus. Bronchoscopic examination at this time,

${ }^{1}$ Present address: Department of Respiratory Diseases and Tuberculosis, University of Edinburgh.

Received for publication 1 October 1964. however, failed to reveal any definite mucosal abnormality in this bronchus or elsewhere.

The patient has been seen at intervals over the three years which have elapsed since the coughing up of the tumour. He has remained in good health and has had no further attacks of wheezing.

The tumour is a firm, whitish, ovoid body (Fig. 1) $2 \mathrm{~cm}$. long and $1.5 \mathrm{~cm}$. wide with a coarsely granular surface. At about the middle of the specimen there is a slender stalk-like appendage a few millimetres long, slightly frayed at its free end. The cut surface shows a thick convoluted layer of opaque white material forming an outer rind within which is enclosed a small central core of brownish connective tissue. Both components are continued into the stalk.

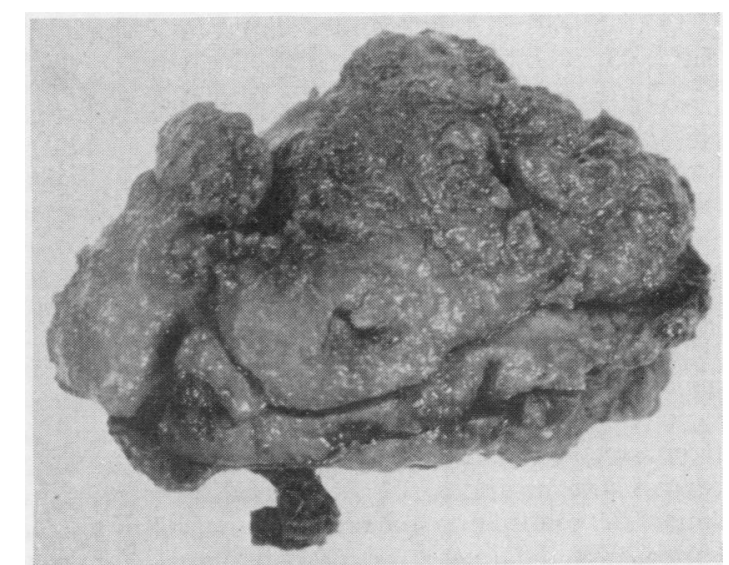

FIG. 1. Pedunculated tumour coughed up by the patient $\left(\times 1 \frac{1}{2}\right)$. 


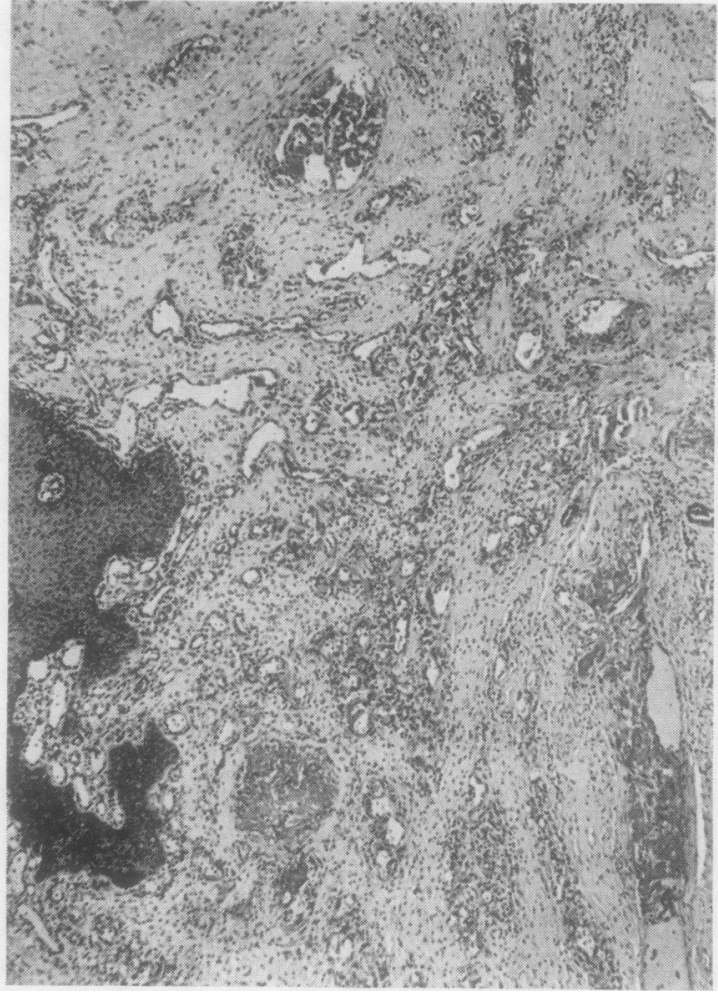

FIG. 2. The vascular stroma of the tumour showing several blood vessels occluded by thrombus $(\times 50)$.

MICROSCOPIC EXAMINATION The white outer layer is hyperplastic squamous epithelium well keratinized at the surface. The connective tissue stroma contains a number of thin-walled blood vessels, several of which are occluded by recent thrombus (Fig. 2). There are also a few foci of acute and chronic inflammatory cells. The stalk has a narrow strip of squamous epithelium down one side, the remainder being amorphous, necrotic tissue.

\section{DISCUSSION}

Papillomas of the bronchus can be divided into three sharply defined groups which appear to differ fundamentally in pathogenesis. 1 Multiple papillomatosis, generally a disease of the young, and probably a virus infection, is characterized by multiple growths, from larynx to bronchiolar level, which ultimately regress and disappear. 2 Inflammatory polyps are single or multiple papillary growths arising from chronically inflamed bronchial mucosa in patients with a long history of chronic respiratory infection. 3 The solitary papilloma is a pedunculated tumour,

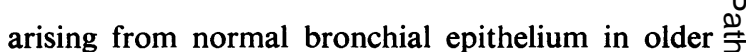
people. It is not characteristically associated with prolonged respiratory infection.

The solitary bronchial papilloma appears to belong to the same class of tumour as the pedunculated papillomas of skin and mucous membranes $\frac{\bar{\sigma}}{\bar{N}}$ and should therefore be regarded as a localized dysplasia, possibly genetically determined, rather $\mathbb{D}$ than a true neoplastic growth. The squamous epi- \& thelium which generally covers the solitary papil- $\vec{O}$ loma in whole or part is evidently a metaplastic change.

The solitary papilloma is by far the rarest of the three types although its true incidence is difficult to? estimate because of the confused nomenclature in $\vec{\infty}$

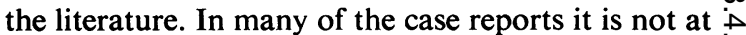
all clear which type of tumour is being described. $A$ Probably the earliest report is that of Siegert (1892) who described a typical example of solitary papilloma of the bronchus found at necropsy in a man of 52 who had had no respiratory symptoms during life. Ashmore (1954) reported the removal of $a$ similar tumour at operation. Ashley, Danino, and $\bar{\varphi}$ Davies (1963) described a case of their own and gave $\circlearrowleft$ details of four others in the literature although they did not include the cases of Siegert and Ashmore. No other fully acceptable case appears to have been reported.

The clinical history is characteristically short, $\mathbb{D}$ lasting a few months to a year or two during which $\stackrel{2}{\Rightarrow}$ time the patient suffers from intermittent attacks of cough and dyspnoea and sometimes from minor episodes of haemoptysis. Asthmatic attacks are not mentioned in the published cases and their occurrence in our patient may have been conditioned by his heredity. His asthmatic attacks in turn, may have brought about the stromal blood vessel thrombosis and subsequent infarction and rupture of the pedicle which resulted in the coughing up of the tumour. None of these features appear in the $\frac{}{2}$ published reports of solitary papilloma of the $D$ bronchus. While it is true that Ashbury (1929) mentions the coughing up of a bronchial tumour the meagre pathological description given does not suggest that it was a solitary papilloma.

We would like to thank Dr. A. C. McLaren for his forethought in preserving the specimen and Dr. I. W. B. Grant for permission to publish.

\section{REFERENCES}

Ashbury, H. E. (1929). Amer. J. Roentgenol, 21, 452

Ashley, D. J. B., Danino, E. A., and Davies, H. D. (1963). Thorax, $18,45$.

Ashmore, P. G. (1954). J. thorac. Surg., 27, 293.

Siegert, F. (1892). Virchows Arch. path. Anat., 129, 413.
$\stackrel{\vec{C}}{\vec{c}}$

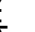
. 